\title{
Analyzing impact of financial information sharing on supply chain performance and stability: system dynamics approach
}

\author{
Tae-Ho Lee*, Jung Ung Min** and Jung-Soo Park***
}

\begin{abstract}
The main streams of the supply chain are defined as material, information and financial flow. There have been many studies and practical cases regarding the flow of material and information including information sharing. However, financial flow related studies have not been widely examined relatively, compared with their importance.

The information sharing is recognized as the method that can reduce the Bullwhip effect in supply chain management. The author intends to analyze the impact of financial information sharing on the results of the supply chain.

In the point of supply chain risk management view, the author examined the impact of financial flow among the various factors that can impede the stability of the supply chain.

In this study, the author embodied the simulation regarding the impact of financial information flow on supply chain performance and stability based on the system dynamics methodology and analyzed the performance.

Assuming the supply chain, composed of supplying company, manufacturing company and sales company, the author embodied the simulation model and assumed that working capital and cash information sharing were achieved. The author embodied the model to affect the settlement conditions according to the results of financial information sharing.
\end{abstract}

Keywords: information sharing, financial information, risk management, system dynamics

Submission Date: 11/23/2010_ Revision Date: 12/15/2010_Acceptance Date: 12/15/2010

* Graduate Student, Graduate School of Logistics, Inha University

** Corresponding Author, Assistant Professor, Asia-Pacific School of Logistics, Inha University, email : jumin@inha.ac.kr

*** Ph.D Stuednt, Graduate School of Logistics, Inha University 


\section{Introduction}

Due to severe competition to maximize profits, competition structure has been changed from competition between companies in markets to competition between supply chains. The globalization of markets and production networks as well as the need for cost-effective management environments for cost-reduction and increased customer' expectation are the main factors which have caused companies to start paying more attention to supply chain management. The flow in the supply chain is composed of material, information and financial flow and it necessitates decision making in the point of overall views for each flow (Lee and Bilington, 1995). ${ }^{1}$ Information sharing is one of the most important factors that affect supply chain results so the partner of the supply chain and information sharing are very important (Lee et al, 1997). ${ }^{2}$ The information includes the following, resources related information such as production capacity, stock, capital and capacity; results related information such as product quality, time, cost and flexibility; and process status related information such as estimate, order, delivery and supplementation (Tae Hoon Kim, 2001). ${ }^{3}$ However, although many researchers have mentioned that the financial flow and financial information sharing are the important factors that affect overall supply chain result, (Kevin Mellyn, Bernard De Groeve, 2001)4 , the studies for financial flow and financial information sharing are relatively restricted and insufficient (Marquez et al, 2004). ${ }^{5}$ Problems in financial flow could cause customer dissatisfaction, sales loss, and profit deterioration which could result in bankruptcy of an enterprise. This phenomenon impedes the stability of supply chains and could be major factor affecting supply chains.

The purpose of this study is to analyze how financial flow and financial information sharing can affect the performance and stability of supply chains. Some studies argue that the three streams in material, information and financial have impact on one another but few studies have been done regarding the impact of financial flow on material flow the supply chain management. This study purposes to understand the mutual relationship among material, information and financial flow in the supply chain and to formalize how financial resources affect material and information flows.

${ }^{1}$ L. H. Lee, Billington, C. (1995) The evolution of supply-chain management models and practice at Hewlett-Packard. Interfaces 25, 42-63.

2 L. H. Lee, Padmanabhan, V., Whang, S. (1997) "The bullwhip effect in supply chains." Sloan Management Review, 38 (3), 93emen

3 Tae-Hoon Kim. (2001) The research regarding the determining factor of information sharing in SCM, University of Yonsei Graduate School of Information Master Degree Thesis

4 Kevin Mellyn, Bernard De Groeve. (2001) "The Argument for Financial-Chain Management." $<$ http://www.cfo.com/article.cfm/3001478> (1 Dec 2001)

5 Adolfo Crespo Marquez, Carmine Bianchi, Jatinder N.D. Gupta. (2004) "Operational and financial effectiveness of e-collaboration tools in supply chain integration" European Journal of Operational Research, $159348 \mathrm{~J} 3$ 


\section{Literature Review}

This section has been completed in terms of risk management in SCM. Three factors of the supply chain, material flow, information flow, and financial flow were the main focus of this review. As for the research methodology, system dynamics were added. The structure of the literature review is described in Figure 1.

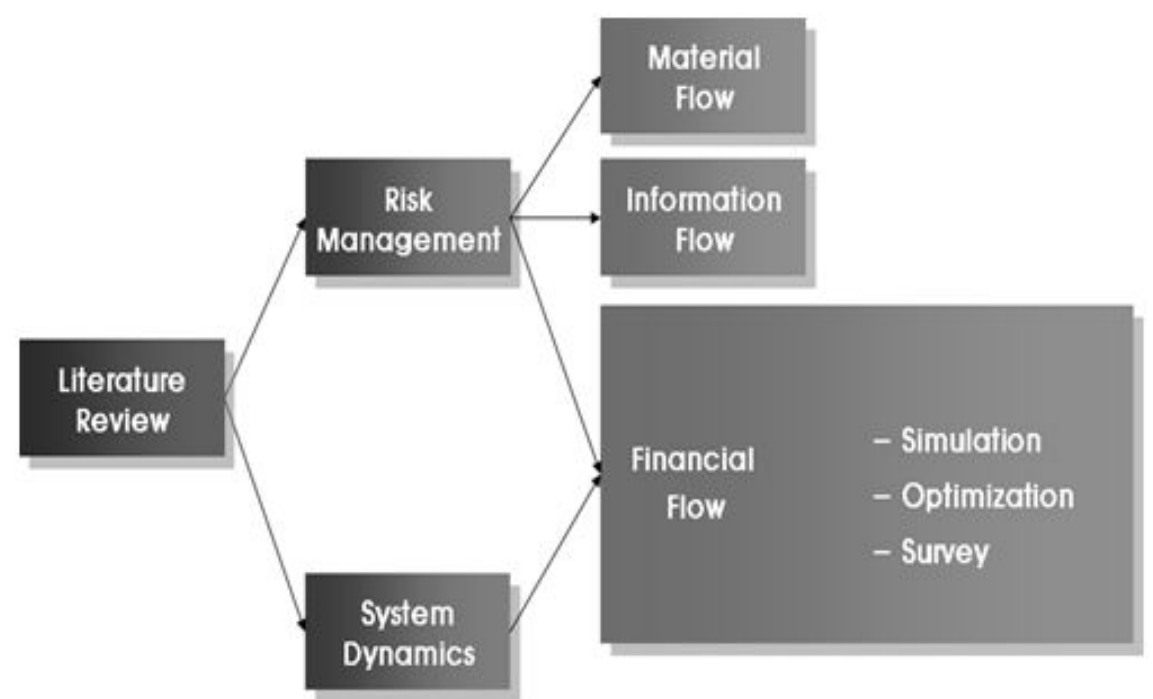

Figure 1.

The structure of the literature review

Jeong et al (2004) suggested 10 various fisk factors in supply chains in Table 1. They also suggested a risk management process and optimization model for investments. ${ }^{6}$

\footnotetext{
6 Jang Hwa Jeong, Young Hea Lee, Jeong Woo Jeong, (2002) “Optimization of collaborative risk management in supply chain management" Korean Institute of Industrial Engineers/The Korean Operations Research and Management Science Society 2002 Spring Joint Academic Tournament
} 


\section{Table 1.}

10 various risk factors in supply chains

\begin{tabular}{c|c}
\hline \multicolumn{2}{c}{ Causes of Risk in Supply Chain } \\
\hline \hline Globalization & Financial Statement \\
\hline Miscommunications & Law and Customer Request \\
\hline Uncertainty of Demand & Various Transaction Relationship \\
\hline Uncertainty of Leadtime & Technology Changes \\
\hline Shorten Product Life Cycle & Fierce Competition \\
\hline
\end{tabular}

Jukka Halikas et al (2004) analyzed the risk management method in the complex network environment. This study showed risk in the supply network resulted from uncertainty and classified risk types into defects of demand information, delivery problems, cost management, and price and resource. Under the supply network environment, they reported risk management processes; however, the study for practical method was not sufficient. ${ }^{7}$

Modh Nishat Faisal et al (2006) suggested 11 methods for the alleviation of risk in the supply chain. As the main methods, they suggested information sharing, reliability with partners, risk or profit sharing, and strategic risk planning. However, the risk alleviation methods are composed of relatively common contents so they are believed to have insufficient new methods. ${ }^{8}$

From the financial flow perspective, Theodore and Hutchison (2002) used cash to cash cycle for cash flow and solvency of enterprise as a mobility measurement tool. Using the cash to cash cycle, based on Dell and JC Penny's cases, they assessed and evaluated circulation speed and cycle. Also, in order to intensify the cash to cash cycle, they suggested three plans as follows; 1) Extend average Account Payable, 2) Shorten the production cycle to reduce inventory days of supply, 3) Reduce average Account Receivable. However, these three resolutions extending average Account Payable and reducing average Account Receivable can be regarded as primary method with lack of reality. ${ }^{9}$

Alea Fairchild (2005) examined the method to increase the flow efficiency of material, information and capital through intelligent matching. Through a case study, KLICT in Holland, confirmed the decrease of asymmetry of the financial information flow, increase

7 Jukka Hallikas, Iris Karvonen, Urho Pulkkinen, Veli-Matti Virolainen, Markku Tuominen, (2004) "Risk management processes in supplier networks" International Journal of Production Economics, 90

8 Mohd Nishat Faisal, D.K. Banwet, Ravi Shankar. (2006) "Supply chain risk mitigation: modeling the enablers" Business Process Management Journal, Vol.12 No.4,

9 M. Theodore Farris II, Paul D. Hutchison (2002) "Cash-to-cash: the new supply chain management metric" International Journal of Physical Distribution \& Logistics Management, Vol. 32 No. 4, 288-298 
of transparency, decrease of transaction costs, and efficiency and increase of financial visibility.

As mentioned earlier, many studies have argued that the supply chain is composed of three kinds of flows material, information and financial. Also, information sharing has been suggested as the main method to raise the results of the supply chain and reduce risk factors. However, it is difficult to find research on the impact of sharing financial information though many have stressed its importance. This study, therefore, analyzes the impact of financial information flow and financial information sharing which have been received less attention but have a lot of influence on the stability of supply chains with regard to risk management.

\section{System Dynamics}

System Dynamics is the simulation methodology to solve the overall complex problems focusing on policy analysis and design. In the beginning, it was called industrial dynamics (Forrester, 1961) and used the concept of information Feedback and Delay in order to understand dynamic behavior of physical, biological and social systems.

System Dynamics has the following characteristics. First, it focuses on dynamic behavior, that is, the behavior changes of systems over time. The fact that it stresses the dynamic features of a system suggests that it cherishes the practical aspects such as changes of a system, evolution, development and decline. It is true that the studies of System Dynamics have contributed to practical political problems and enterprise problems as application studies rather than pure studies. The fact that the methodology of System Dynamics has been adopted by numerous consulting enterprises with higher speed suggests this.

Second, System Dynamics seeks out the fundamental reasons of dynamic changes from the feedback structure. The feedback structure refers to the closed circuit that forms as the cause and effect relationship between variables is mutually connected (Richardson 1991). The concept of feedback structure or feedback loop is used as the meaning of general term of circulating cause and effect relationships differently from the control engineering or group theory. The highlight for feedback structure implies diverse methodological suggestions.

Th fact that it highlights the feedback structure means that it is designed to discover the changes of a system from endogenous variables rather than exogenous variables. As long as the changes of the system are explained by exogenous variables, it is difficult to change the system's behavior. However, when it is possible to explain the changes of the system in endogenous variables, it is possible to change the system formation within the model. System Dynamics is a very useful tool for modeling the interactions among information, capital, order and complex flow products in supply chains (U.M. Bhushi, 2004). For this reason, this study uses system dynamics in order to structure the simulation model and to analyze the results. 


\section{Simulation Modeling}

\subsection{Basic Modeling Concept}

The simulation model involves one Echelon supply chain which is composed of a supplier, manufacturer and seller. It modelizes the mutual organic flow of material, information and Funds.

As a basic major premise, the author establishes that the supplier, manufacturer and seller regulate the settlement means and conditions through working capital information sharing.

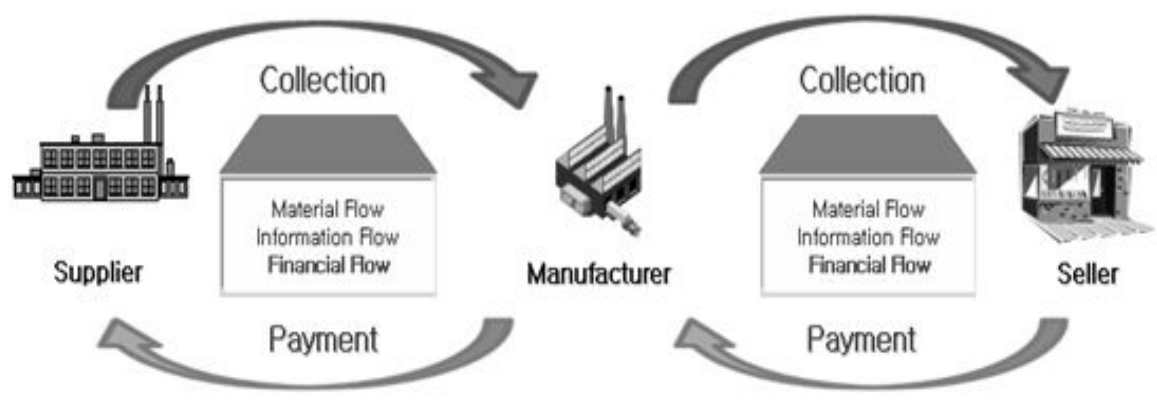

Figure 2.

The model of material flow

The model of material flow is shown in Figure 2, including, information flow and financial flow with the supply chain composed of supplier, manufacturer and seller. Each flow of this model is shared and affects decision making regarding the settlement and payment between each player.

The financial flow affects material flow and information flow. For example, when the supplementary order information of the manufacturer is transmitted to supply agents, if the buyer has no solvency, the material is not supplemented. Also, if the supplier, manufacturer and sellers do not acquire the minimum capital for main activities such as production, sales and purchase of each player, it could cause abnormal management with management problems. 


\subsection{Simulation Design}

This study is based on the major premise that it is possible to share financial information between partners within the supply chain. In the general deal relation, if the financial information of cooperative companies is acquired unofficially, without public announcement or audit report, it is not considered a traditional acquirement. Therefore, in this study, we assumed the financial information sharing could be achieved under the reliability-based condition owing to long-term deal relationship.

Assumption 1. The partners within the supply chain share mutual financial information. Assumption 2. The supply chain is composed of sales agents, manufacturers and suppliers. Assumption 3. The production capacity of suppliers and manufacturers is unlimited. Assumption 4. The due date for accounts receivable and accounts payable is only 30 days. Assumption 5. The debt from the bank should be repaid after 90 days.

Assumption 6. If the debt rate is over $200 \%$, it is impossible to issue the Account Payable. Assumption 7. Purchasing one material, it produces and sells one product. Assumption 8. If the cash is insufficient for management, production is stopped. Assumption 9. The available settlement means during the deal between each player in supply chain is shown in Table 2.

Table 2.

The available settlement means during the deal between each player in supply chain is shown

\begin{tabular}{c|c}
\hline Players in Supply Chain & Available Payment Term \\
\hline \hline Dummy Supplier & Cash \\
\hline Supplier & $\begin{array}{c}\text { Cash } \\
\text { Account Receivable }\end{array}$ \\
\hline Manufacturer & $\begin{array}{c}\text { Cash } \\
\text { Account Receivable } \\
\text { Account Payable }\end{array}$ \\
\hline Seller & Cash \\
Account Payable \\
\hline Dummy Customer & Cash \\
\hline
\end{tabular}

As for the demand pattern, the following scenario (depicted in Table 3) has been used. 
Table 3.

As for the demand pattern, the following scenario

(Unit: ea/day)

\begin{tabular}{|c|c|c|}
\hline Demand Distribution & Mean & Standard Deviation \\
\hline \multirow{9}{*}{ Normal Distribution } & \multirow{3}{*}{100} & 10 \\
\hline & & 20 \\
\hline & & 30 \\
\hline & \multirow{3}{*}{200} & 10 \\
\hline & & 20 \\
\hline & & 30 \\
\hline & \multirow{3}{*}{300} & 10 \\
\hline & & 20 \\
\hline & & 30 \\
\hline \multirow{3}{*}{ Exponential Distribution } & 100 & \\
\hline & 200 & \\
\hline & 300 & \\
\hline
\end{tabular}

In order to perform comparative analysis for capacity and results of models of each demand function, normal distribution and exponential distribution demand function were used. For normal distribution, three types of pattern averages (100 ea/day, 200 ea/day, 300 ea/day) and three types of standard deviation (10 ea/day, 20 ea/day, 30 ea/day) were set. In the case of exponential distribution, three types of average patterns (100ea/day, 200ea/day, 300ea/day) were set. Since it was expected that the simulation model reaction could be presented differently according to demand variability, the author intends to analyze the impact by applying the distribution with diverse average and standard deviation.

\subsection{Simulation Scenario}

In order to analyze the effects of financial information sharing, we designed the "To-Be Model" and "As-Is Model." The differences are shown in Table 4. 


\section{Table 4.}

The difference of the "To-Be Model" and "As-Is Model."

\begin{tabular}{c|c|c}
\hline Feature & As Is & To Be \\
\hline \hline $\begin{array}{c}\text { Consideration of supplier's cash statement at } \\
\text { payment by manufacturer }\end{array}$ & $\mathrm{X}$ & $\mathrm{O}$ \\
\hline $\begin{array}{c}\text { Consideration of manufacturer's cash } \\
\text { statement at payment by seller }\end{array}$ & $\mathrm{X}$ & $\mathrm{O}$ \\
\hline
\end{tabular}

If the manufacturer has sufficient cash, but the supplier does not have sufficient cash, through financial information sharing, it can change the settlement from Account Payable to cash in order not to make supplier raise funds with high interest so as to reduce the overall cost of supply chain. Also, it is expected that it can prevent the problems in management of supplier due to cash deficiency in advance so that it can raise the stability of supply chain.

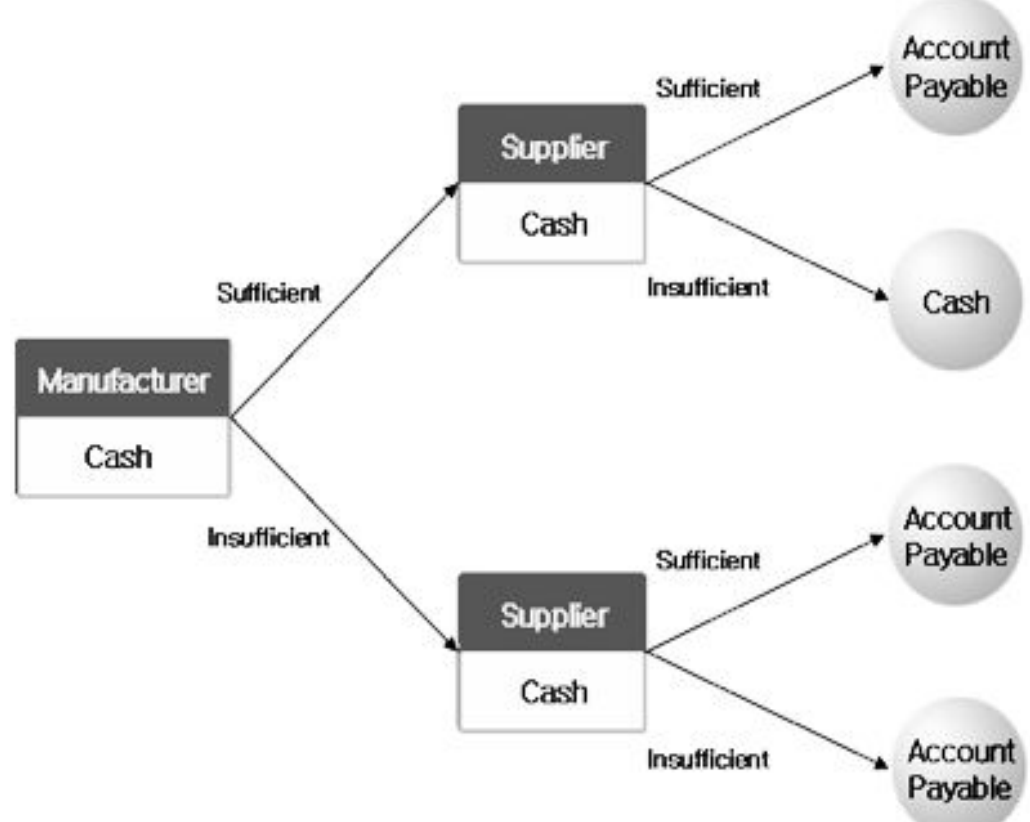

Figure 3.

Simulation Scenario 


\subsection{Causal Loop Diagram}

There are Positive Loop and Negative Loop in the Causal Loop Diagram. In Figure 4, "O" indicates a Positive Loop while "S" indicates a Negative Loop. The Causal Loop Diagram can be explained with two parts; material flow on left side and financial flow on right side. The material flow and financial flow are not interdependent.

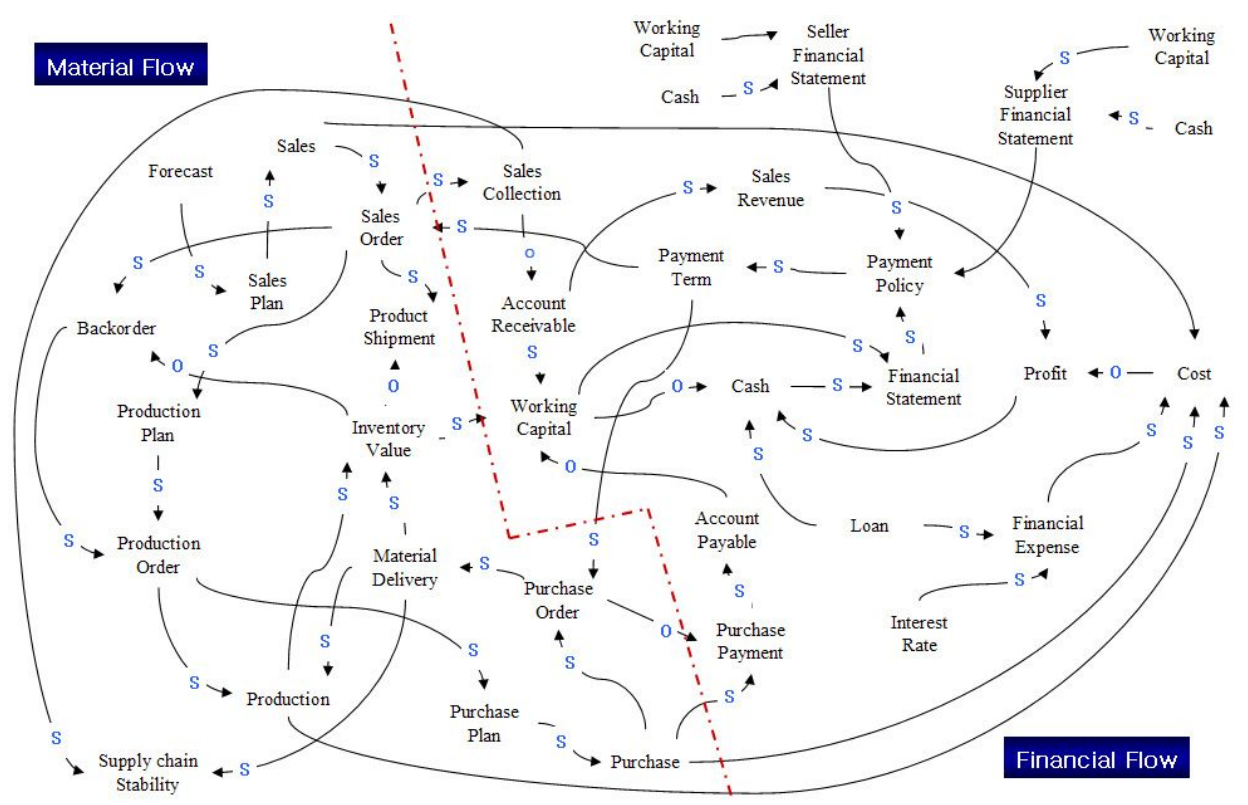

Figure 4.

Causal Loop Diagram

In financial flow loop, the increase and decrease of stock affects working capital, sales affects Account Receivable, and cash and Account Receivable affects working capital. Also, purchases affect Account Payable, and cash and Account Payable affect working capital. All the production, purchases and sales activity affect cost and the cost affects profit while profit affects cash. Working capital as well as cash status affect financial status, financial status affects payment policy, and payment policy affects payment terms in the end. 


\subsection{Simulation Model}

The Figure 5 shows the purchase, production and sales process regarding materials of manufacturer.

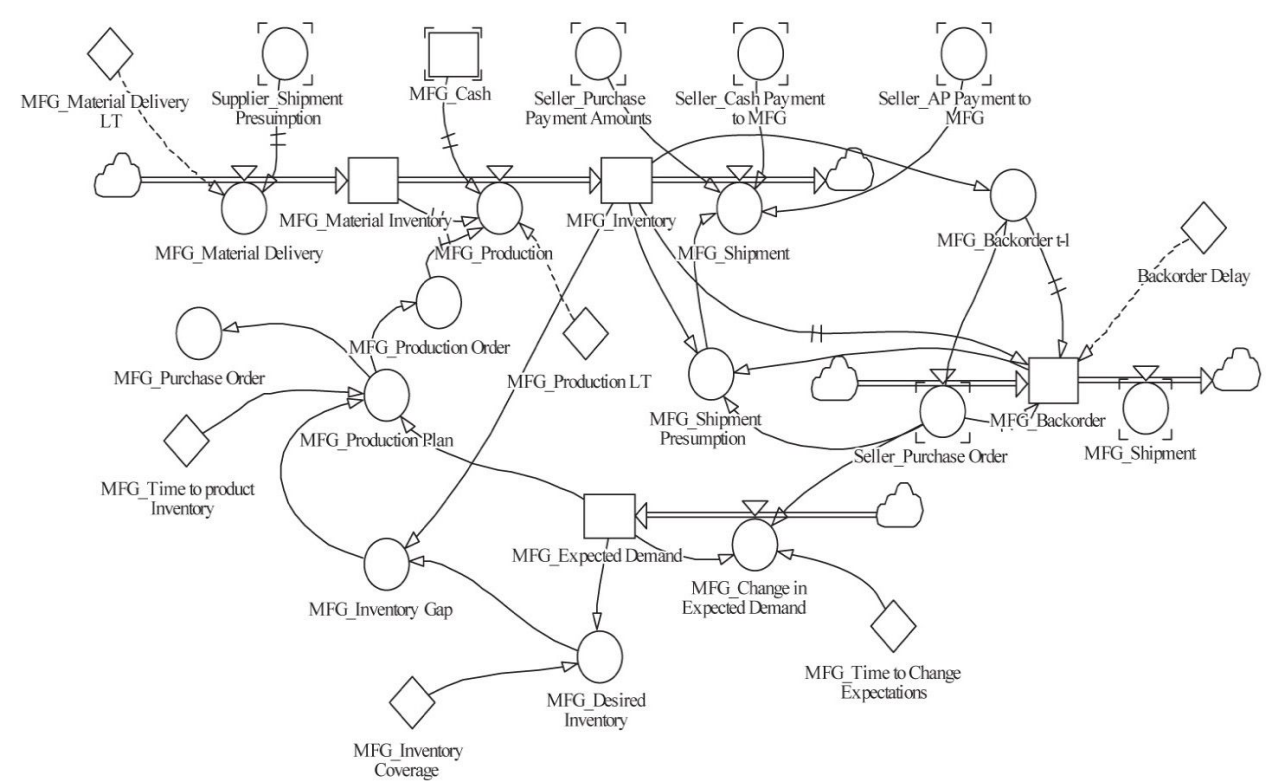

Figure 5.

Purchase, production and Sales process of manufacturer

According to the seller's orders and own demand estimate, production or purchase plans are established to maintain the stock amount. Purchase orders and production order are executed by the plan and when the stock is supplemented, it is delivered to the seller. Only when the seller pays with cash or account payable, the delivery is made. The order which is not delivered due to insufficient stock, is saved as Backorder and comes to affect the further production or purchase plan. It is connected with material flow, and is shown in Figure 6, along with the financial settlement and flow. 


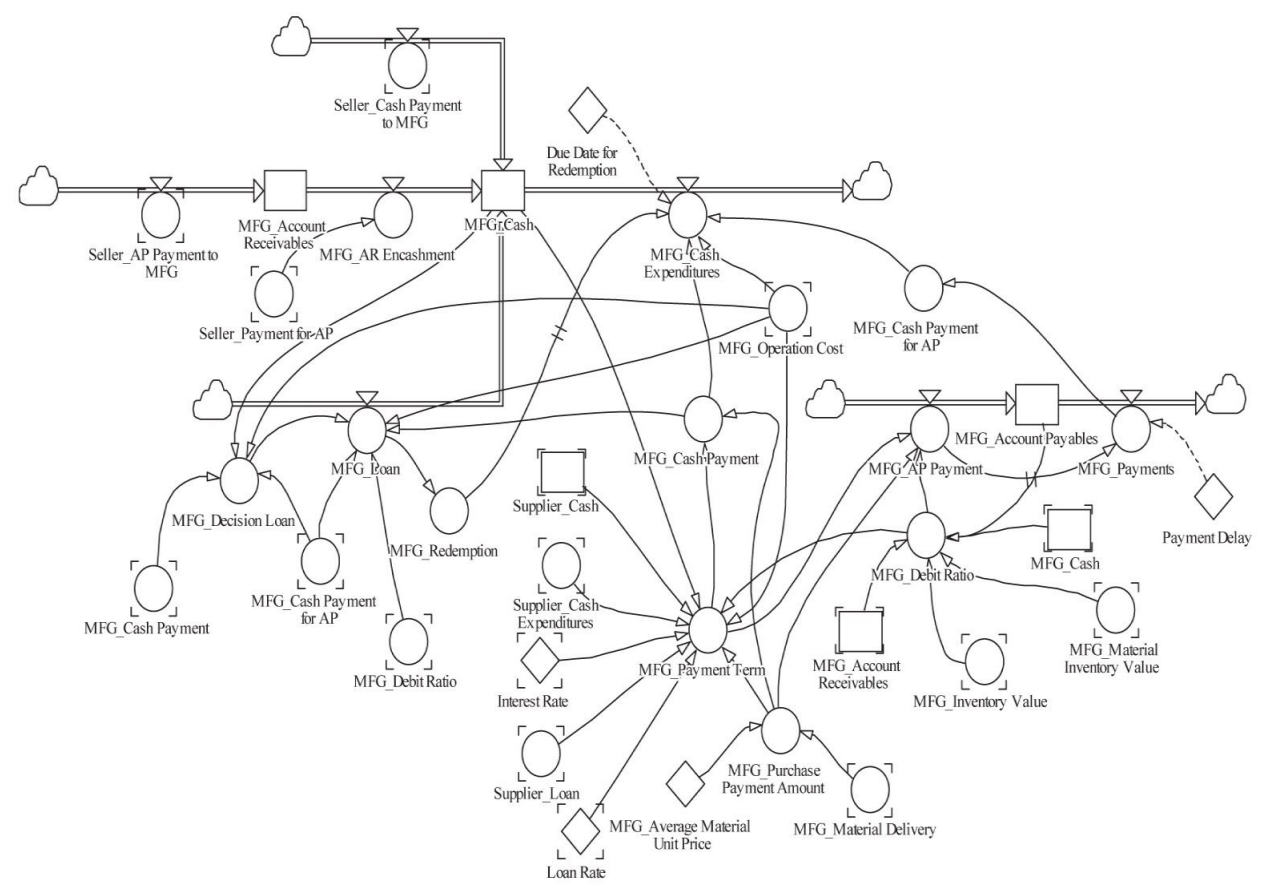

Figure 6.

Material flow

We composed the flow of cash, account payable and account receivable according to purchase or sales. Also, setting the variables for settlement condition selection, the author modeled in order to select according to the flow of cash and bills. Drawing a bill was restricted only when the debt rate was less than $200 \%$. It was designed to be managed with loans when cash was not sufficient.

The working capital is composed of inventory, accounts payable and accounts receivable as shown in Figure 7. 


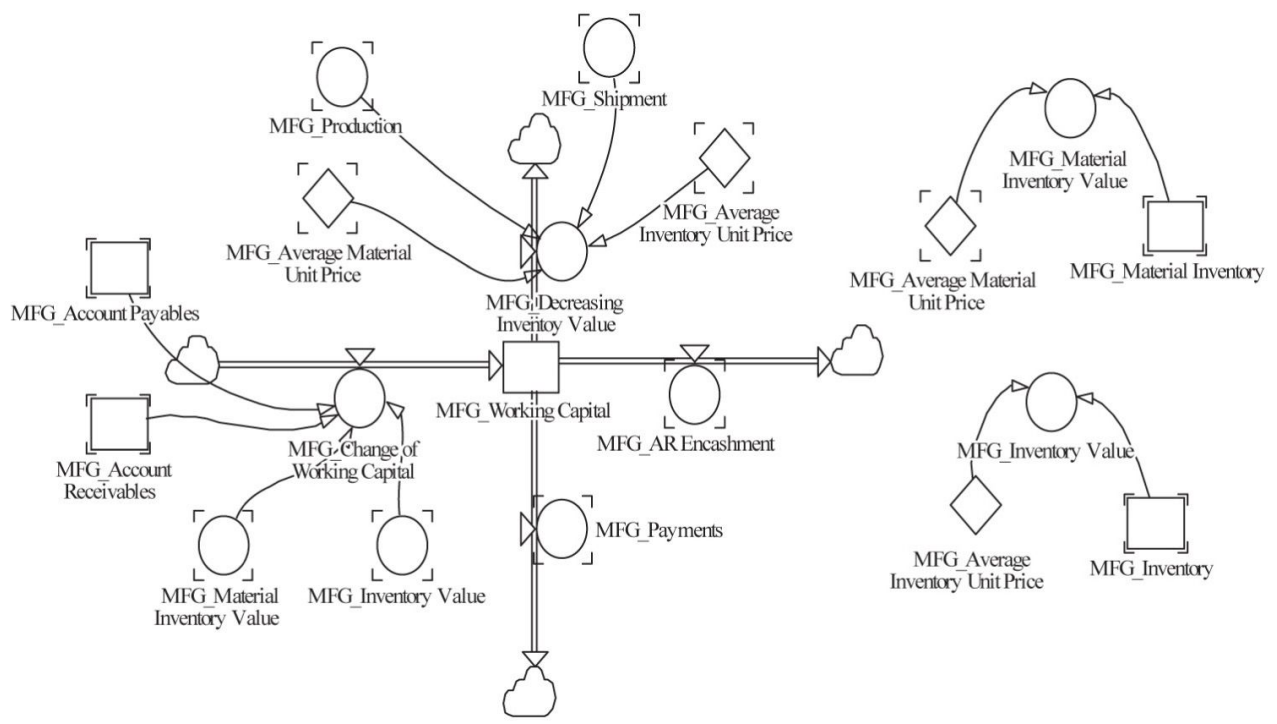

Figure 7.

Working Capital Composition

The value can be increased by the generation of stock and accounts receivable and it can be decreased by accounts payable. The value is decreased by encashment from the expiration of bills and stock confining. Stock value is calculated multiplying the stock amount by unit cost and it is changed by stock increase and decrease.

Figure 8 shows the model that describes cost generation structure and profit creation structure according to manufacturer management. 


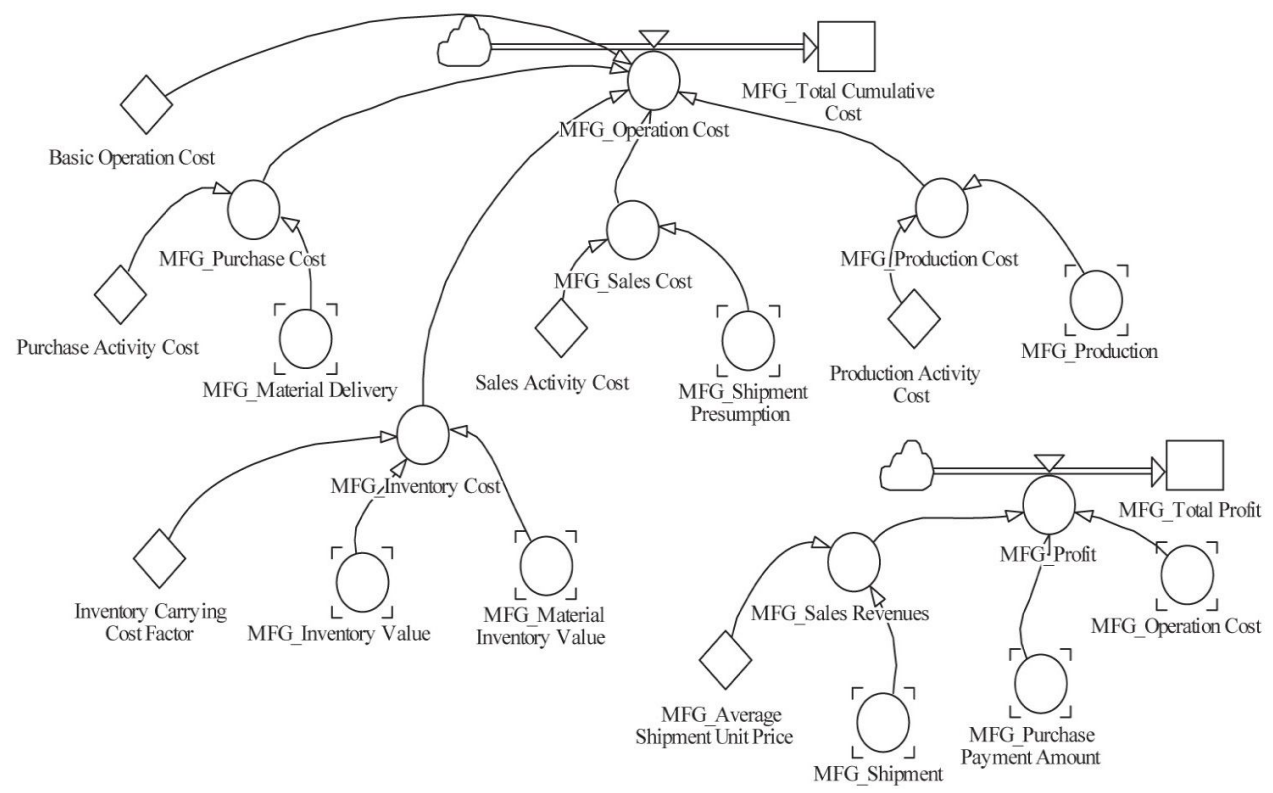

Figure 8.

Cost and profit Structure

The cost structure is composed of basic management cost, purchase activity cost, production activity cost, sales activity cost and stock cost. The profit is organized to calculate except cost in the sales revenues of the manufacturer.

System Dynamics models for suppliers and sellers have been developed with a similar concept and they were incorporated as one big simulation model.

\section{Simulation Results}

\subsection{Key Performance Index}

The key performance index (KPI) for the analysis of simulation result has been identified and is shown in Table 5. The KPIs were classified by performance aspect and stability and intends to measure and assess with 6 factors. 


\section{Table 5.}

The key performance index (KPI) for the analysis of simulation result

\begin{tabular}{c|c|l}
\hline & Factors & \multicolumn{1}{c}{ Definition } \\
\hline \hline \multirow{4}{*}{ Performance } & Operation Cost & $\begin{array}{l}\text { Basic + Production + Purchase + Sales + } \\
\text { Inventory Cost }\end{array}$ \\
\cline { 2 - 3 } & Sales Revenue & Sales Unit Price $\times$ Sales Amount \\
\cline { 2 - 3 } & Total Profit & $\begin{array}{l}\text { Sales Revenue - Operation Cost }- \text { Payment } \\
\text { Amount }\end{array}$ \\
\hline \multirow{3}{*}{ Stability } & Backorder Level & Purchase Order - Inventory \\
\cline { 2 - 3 } & Inventory Level & Material Inventory + Product Inventory \\
\cline { 2 - 3 } & Cash Flow & Cash Level \\
\hline
\end{tabular}

\subsection{Simulation Results}

\subsubsection{Performance KPI}

As for the operation cost, supplier, manufacturer, and supplier's operation costs were higher in the "To-be Model" as shown in Figure 9. The reason was that due to lack of cash in the "As Is" Model, the operation was not undertaken properly, in other words, they were idle, so that no cost was incurred.

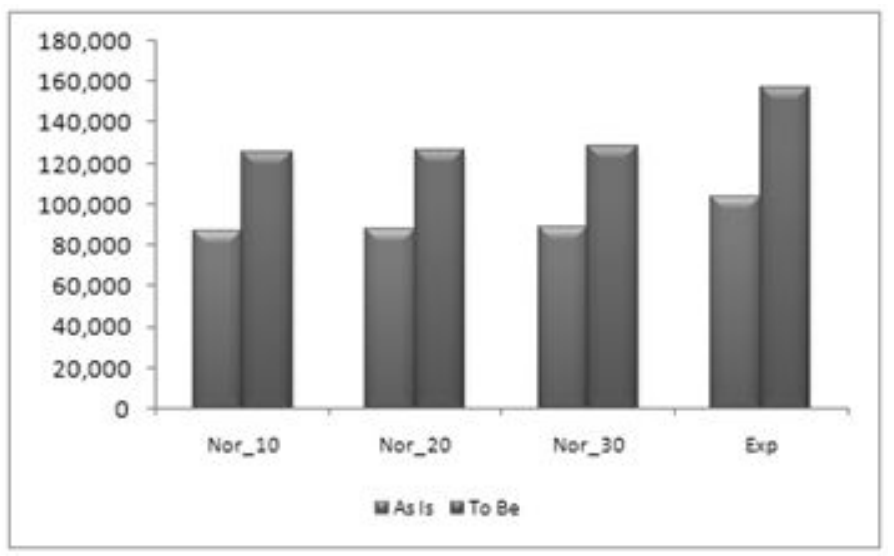

Figure 9.

Operation Cost 
On the other hand, sales revenues show a different pattern that it was high in To-be model. The sales revenue of the To Be Model showed bigger changes of exponential distribution compared with normal distribution. The reason is that exponential distribution has bigger demand variability than normal distribution so that generation of demand is bigger. The To Be Model has little sales loss due to little stock-out. Figure 10 shows sales revenues of manufacturers.

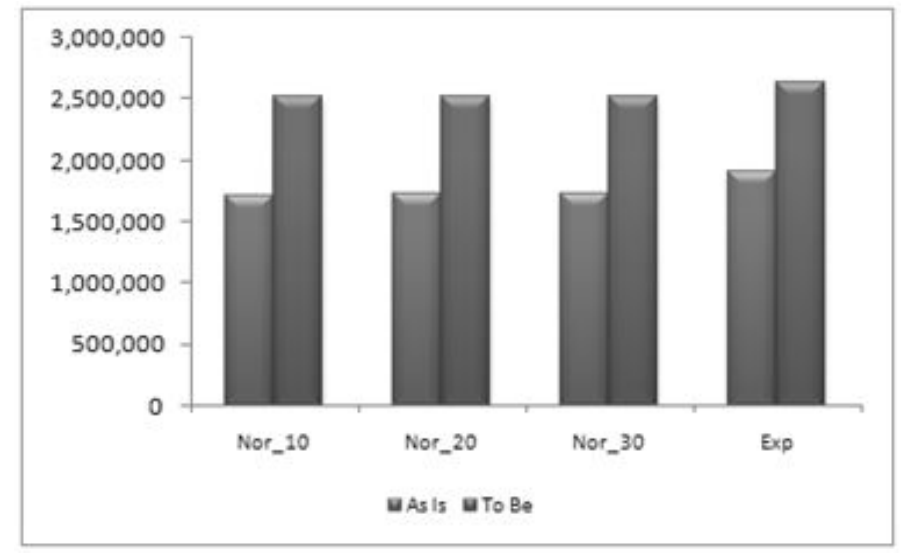

Figure 10.

Sales revenue of manufacturer

Table 6.

Comparing As-Is vs. To-Be

(Unit: USD/day)

\begin{tabular}{c|c|c|c}
\hline & As Is & To Be & Ratio \\
\hline \hline Normal_10 & $1,716,893.96$ & $2,522,516.91$ & 1.47 \\
\hline Normal_20 & $1,720,782.39$ & $2,518,027.80$ & 1.46 \\
\hline Normal_30 & $1,725,798.50$ & $2,513,541.00$ & 1.46 \\
\hline Exponential & $1,902,380.00$ & $2,625,592.07$ & 1.38 \\
\hline
\end{tabular}

Cost and sales revenue increased simultaneously in the To Be Model. Though operation cost has been increased, net profits show huge differences between the two models. Figures 11, 12, and 13 shows the profits of suppliers, manufacturers, and sellers respectively. 


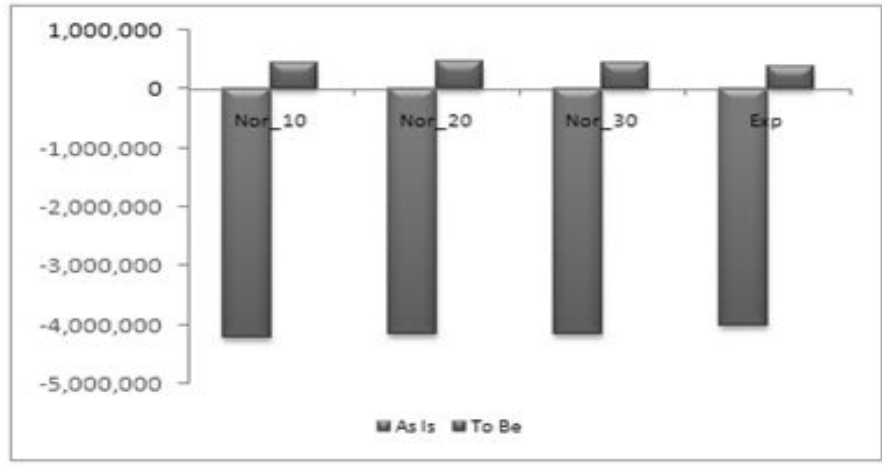

Figure 11.

Profits of Supplier

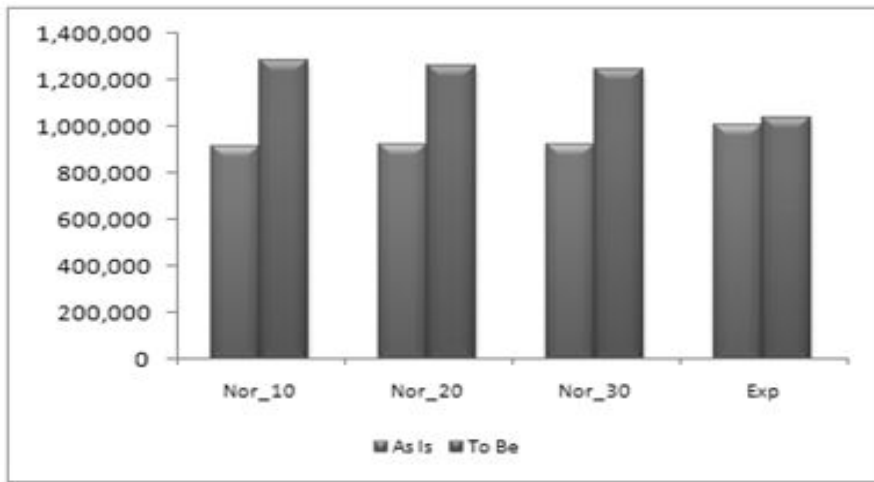

Figure 12.

Profits of manufacturer

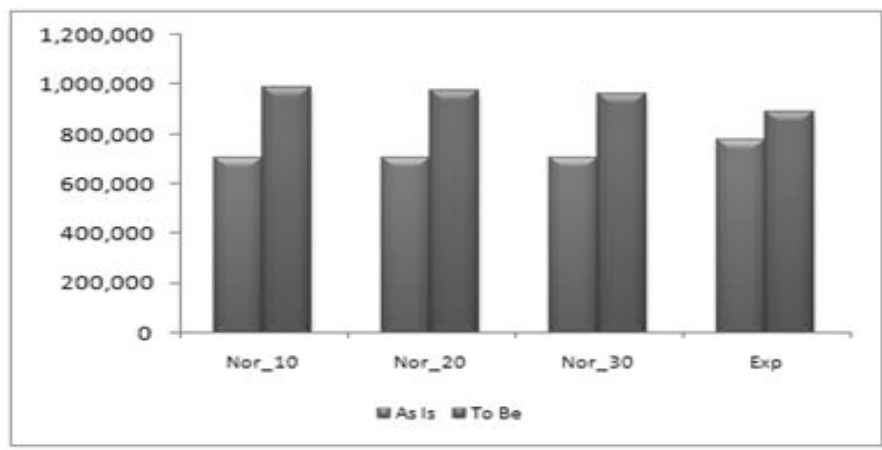

Figure 13.

Profits of Seller 
Figure 14 shows that the profit level is deteriorated from the starting point when stock-out has occurred. Also due to the deterioration of supplier's earning power, it shows that the earning power of the overall supply chain is also deteriorated.

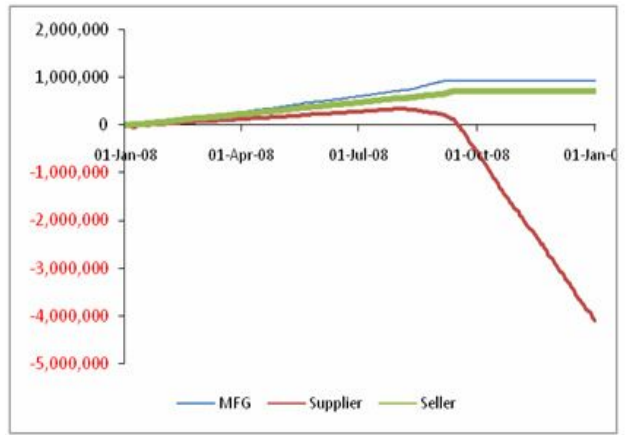

<As Is Model>

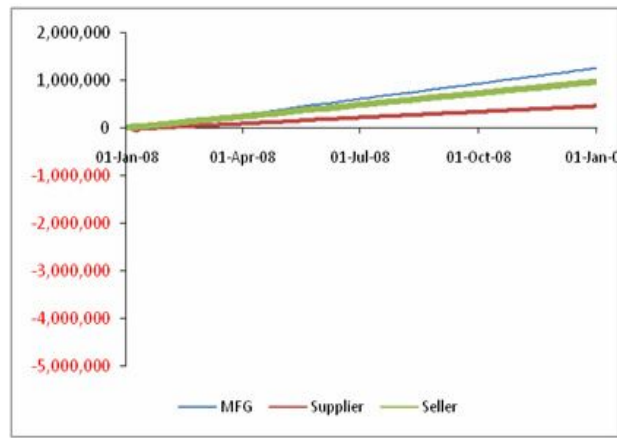

$<$ To Be Model>

Figure 14.

Profit level Comparison

Table 7.

Profit level Comparison with ratio

(Unit: USD)

\begin{tabular}{c|c|c|c|c}
\hline & Supplier & Manufacturer & Seller & SUM \\
\hline \hline As Is & $718,229.58$ & $1,725,798.497$ & $172,121,956.18$ & $463,465,971$ \\
\hline To Be & $203,919,504.94$ & $-173,474,472.48$ & $160,505,100.81$ & $190,950,133$ \\
\hline Ratio & 1.06 & 3.30 & 1.07 & 2.42 \\
\hline
\end{tabular}




\subsubsection{Stability KPI}

The backorder level by normal distribution is shown in Figure 15.

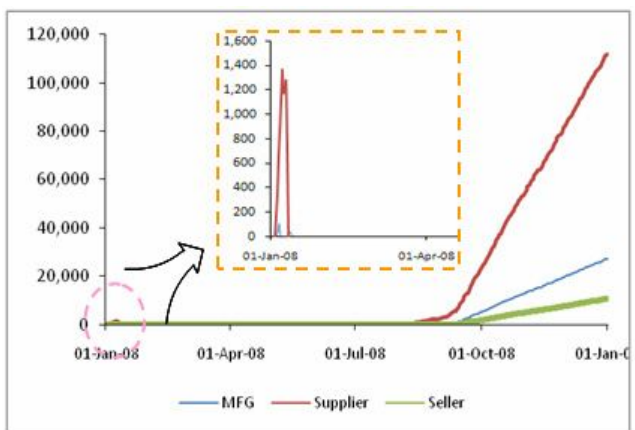

< As Is Model >

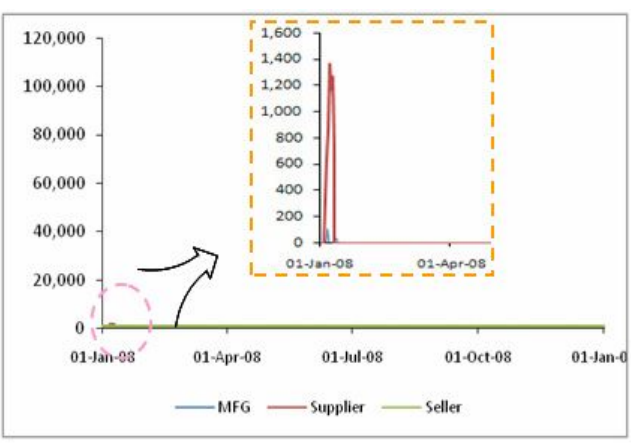

<To Be Model>

Figure 15.

Backorder in normal distribution

The early backorder level of the As Is and To Be Models is identical; however, as time goes by, due to lack of cash, The As Is Model stops production, which causes increase of the backorder level. On the other hand, during the simulation, with the smooth cash flow, the To Be Model can maintain a stable supply operation without backorder occurrence.

Backorder level by exponential distribution is shown in Figure 16.

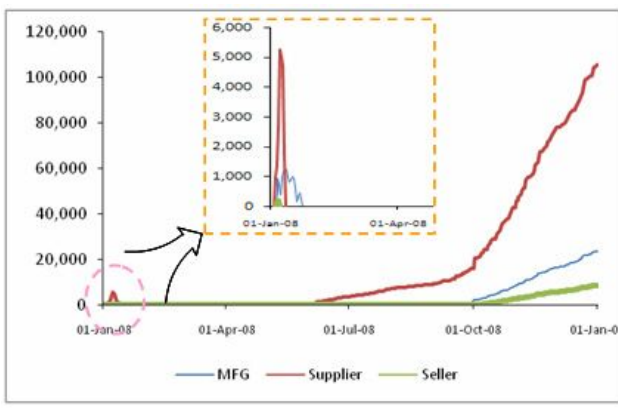

<As Is Model>

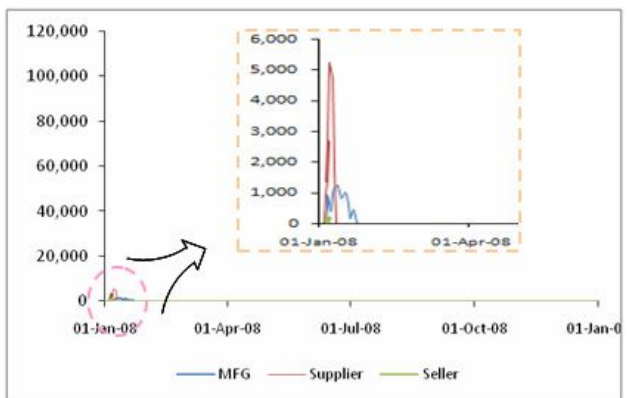

<To Be Model>

Figure 16.

Backorder in exponential distribution 
This research reveals that in the exponential distribution, in the To Be Model, the backorder level improved after a while.

Through Table 8 and 9, we can see that when we analyze the As Is Model and To Be Model according to the two kinds of demand functions, in the As Is Model, regarding the average and standard deviation of backorders of suppliers, manufacturers and sellers, the normal distribution is high, while the exponential distribution is high in the To Be Model.

Table 8.

Comparison of backorders with different demand function

(Unit: ea)

\begin{tabular}{c|c|c|c|c|c}
\hline \multicolumn{2}{c|}{ Factor } & Supplier & Manufacturer & Seller & SUM \\
\hline \hline Normal & Mean & $18,052.68$ & $4,252.51$ & $1,610.78$ & $23,915.97$ \\
\hline Exponential & Mean & $17,419.17$ & $3,135.11$ & $1,008.29$ & $21,562.57$ \\
\hline & Ratio & 1.04 & 1.36 & 1.60 & 1.11 \\
\hline Normal & SD & $31,878.17$ & $7,723.95$ & $2,980.18$ & $42,582.29$ \\
\hline Exponential & SD & $28,320.34$ & $6,228.20$ & $2,181.27$ & $36,729.80$ \\
\hline & Ratio & 1.13 & 1.24 & 1.37 & 1.16 \\
\hline
\end{tabular}

Table 9.

Comparison of backorders with different demand function

(Unit: ea)

\begin{tabular}{c|c|c|c|c|c}
\hline \multicolumn{2}{c|}{ Factor } & Supplier & Manufacturer & Seller & SUM \\
\hline \hline Normal & Mean & 17.72 & 0.43 & 0 & 18.15 \\
\hline Exponential & Mean & 60.54 & 38.43 & 0.92 & 99.89 \\
\hline & Ratio & 0.29 & 0.01 & - & 0.18 \\
\hline Normal & SD & 135.15 & 5.80 & 0 & 140.95 \\
\hline Exponential & SD & 492.46 & 182.37 & 12.64 & 687.48 \\
\hline & Ratio & 0.27 & 0.03 & - & 0.21 \\
\hline
\end{tabular}


As for the inventory level, the following figure describes the inventory level in cases of normal distribution as demand pattern.

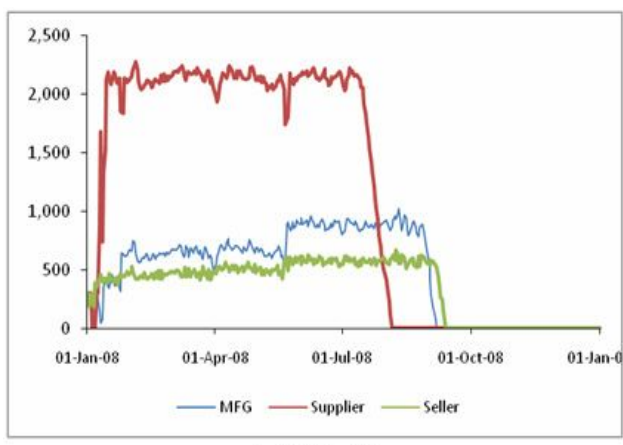

<As Is Model>

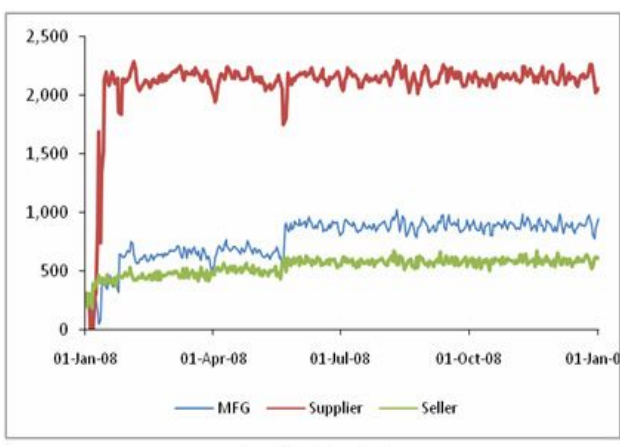

< To Be Model $>$

Figure 17.

Inventory level of 2 models

When stock-out occurred to suppliers, manufacturers, and sellers in the As Is Model, most of the sales opportunity was lost. However, in the To Be Model, it is possible to acquire sufficient inventory so that the stock-out does not occur during the simulation period.

If we analyze the stock pattern according to exponential and normal distribution, the exponential distribution holds more stock compared with normal distribution. This is because the exponential distribution has a relatively bigger range of fluctuation in demand.

Table 10.

Comparison of stock with different demand function

(Unit: ea)

\begin{tabular}{c|c|c|c|c|c}
\hline \multicolumn{2}{c|}{ Factor } & Supplier & Manufacturer & Seller & SUM \\
\hline \hline Normal & Mean & 1149.77 & 477.24 & 349.91 & 1976.92 \\
\hline Exponential & Mean & 2005.24 & 1564.37 & 1090.57 & 4660.19 \\
\hline & Ratio & 0.22 & 0.31 & 0.34 & 0.25 \\
\hline Normal & SD & 1034.78 & 365.33 & 241.25 & 1641.35 \\
\hline Exponential & SD & 2923.38 & 1312.20 & 702.35 & 4937.94 \\
\hline & Ratio & 0.17 & 0.21 & 0.22 & 0.18 \\
\hline
\end{tabular}


Table 11.

Comparison of stock with different demand function

(Unit: ea)

\begin{tabular}{c|c|c|c|c|c}
\hline \multicolumn{2}{c|}{ Factor } & Supplier & Manufacturer & Seller & SUM \\
\hline \hline Normal & Mean & 2084.11 & 772.22 & 530.56 & 3386.89 \\
\hline Exponential & Mean & 9474.78 & 2501.44 & 1546.48 & 13522.71 \\
\hline & Ratio & 0.22 & 0.31 & 0.34 & 0.25 \\
\hline Normal & SD & 316.23 & 174.18 & 71.60 & 562.01 \\
\hline Exponential & SD & 1883.24 & 836.96 & 321.69 & 3041.89 \\
\hline & Ratio & 0.17 & 0.21 & 0.22 & 0.18 \\
\hline
\end{tabular}

The cash flow in normal distribution is shown in Figure 18.

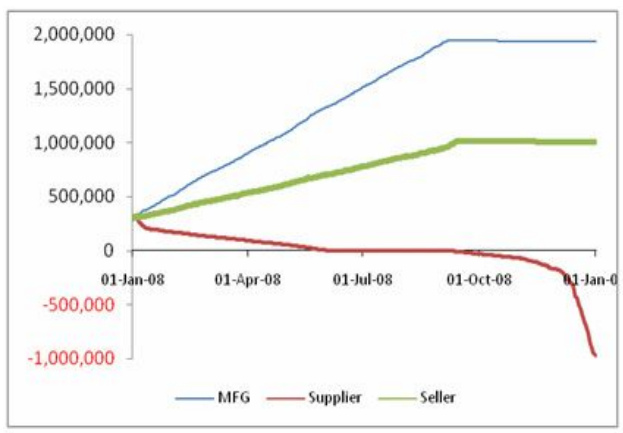

<As Is Model>

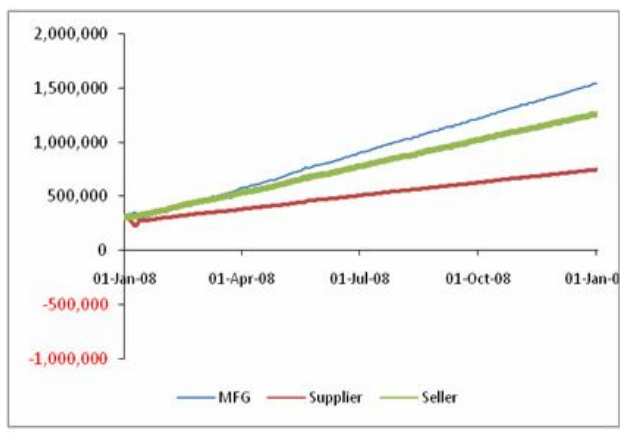

<To Be Model>

\section{Figure 18.}

The cash flow in normal distribution

Regarding the cash of the As Is Model, the supplier shows poor cash flow patterns. Also, after the some duration, it shows a cash deficiency phenomenon. On the other hand, it shows that during the initial normal purchase, production and sales are made in manufacturers and suppliers, the cash is increased but the cash deficiency is occurred to supplier so that the cash flow is gradually deteriorated.

On the contrary, the To Be Model shows relatively stable cash flow with a continuous increase of cash. In the end, it is believed that financial information sharing affects cash flow in case the demand function is normal distribution. 


\subsubsection{Discussion}

In order to grasp the impact of financial information sharing on the performance and stability of supply chain, a System Dynamics model was constructed and the effects of financial information sharing on KPI was analyzed.

Through the financial information sharing, the performance of the supply chain was improved and its stability was enhanced. These improvements were connected to the enhancement of the stability of the supply chain, which formed a circulation structure.

In the end, from the risk management perspective, it was discovered that the risk factor was decreased so the supply chain could be managed stably.

As the financial resource levels of the supply chain become stable, it can be concluded that financial information sharing can affect the stabilization of financial resources. This is known as the "Financial Bullwhip Effect", comparing it with the early Bullwhip Effect as shown in Table 12.

Table 12.

The "Financial Bullwhip Effect", comparing it with the early Bullwhip Effect

\begin{tabular}{c|l|l}
\hline Factor & \multicolumn{1}{|c}{ Bullwhip Effect } & \multicolumn{1}{c}{ Financial Bullwhip Effect } \\
\hline \hline \multirow{3}{*}{ Definition } & $\begin{array}{l}\text { The phenomenon of extending } \\
\text { request level for inventory with } \\
\text { demand fluctuation }\end{array}$ & $\begin{array}{l}\text { The phenomenon of extending } \\
\text { request level for financial resource } \\
\text { with demand fluctuation }\end{array}$ \\
\hline \multirow{3}{*}{ Causes } & $\begin{array}{l}\text { Demand signaling } \\
\text { Order batching } \\
\text { Fluctuation prices } \\
\text { Shortage game }\end{array}$ & $\begin{array}{l}\text { Information discontinuance for } \\
\text { financial resource }\end{array}$ \\
\hline & $\begin{array}{l}\text { Information Sharing } \\
\text { Channel Alignment } \\
\text { Operational Efficiency }\end{array}$ & Financial Information Sharing \\
\hline
\end{tabular}

\section{Conclusion}

Among the main three flows in supply chain management, this study analyzed the financial flow and information sharing, which are relatively less examined, using System Dynamics methodology. Through this study, a mutual relationship among material, information and financial flow was identified. The author confirmed that the three kinds of flows and information were not transmitted in the supply chain independently but affecteds the overall supply chain performance with mutual relationship . 
This could be somewhat restrictive and unrealistic but we could observe this phenomenon through the simulation as well as the relationship with supply chain performance.

It has been widely known that sharing information with partners in the supply chain is beneficial, but at the beginning of SCM ear, it was not common to see the value of sharing the forecasting information and inventory information with partners in a supply chain. As information sharing remedied the curse of the Bullwhip Effect, so does financial information sharing do the same for the Financial Bullwhip Effect. Sharing financial information can be unrealistic but it was observed that financial information sharing is worthy .

As for the limitation of the research, we have assumed a 1-Tier Supply Chain model which might be too simplified considering industry practices. In addition, the demand pattern, could have been conducted with more various conditions, instead of the simple demand pattern that was utilized.

\section{Acknowledgements}

This work was supported by INHA UNIVERSITY Research Grant.

\section{References}

Adolfo Crespo Marquez, Carmine Bianchi, Jatinder N.D. Gupta. (2004)

"Operational and financial effectiveness of e-collaboration tools in supply chain integration" European Journal of Operational Research, 159 348-63

Alea Fairchild. (2005) "Intelligent matching: integrating efficiencies in the

financial supply chain" Supply Chain Management: An International Journal, Vol.10 No.4 244-248

Jang Hwa Jeong, Young Hea Lee, Jeong Woo Jeong, (2002) “Optimization of collaborative risk management in supply chain management" Korean Institute of Industrial Engineers/The Korean Operations Research and Management Science Society 2002 Spring Joint Academic Tournament

Jukka Hallikas, Iris Karvonen, Urho Pulkkinen, Veli-Matti Virolainen, Markku Tuominen, (2004) "Risk management processes in supplier networks" International Journal of Production Economics, 90

Kevin Mellyn, Bernard De Groeve. (2001) "The Argument for Financial-Chain Management." $<$ http://www.cfo.com/article.cfm/3001478> (1 Dec 2001)

L. H. Lee, Billington, C. (1995) The evolution of supply-chain management models and practice at Hewlett-Packard. Interfaces 25, 42-63.

L. H. Lee, Padmanabhan, V., Whang, S. (1997) "The bullwhip effect in supply chains." 
Sloan Management Review, 38 (3), 93), 9

M. Theodore Farris llwhip effect in supply chains. Sloan Management Review, 38 (3), 93), 933), 9338 (3), 932-63.25, 42-63.25, 42-63.n

Distribution \& Logistics Management, Vol. 32 No. 4, 288-298.

Mohd Nishat Faisal, D.K. Banwet, Ravi Shankar. (2006) "Supply chain risk mitigation: modeling the enablers" Business Process Management Journal, Vol.12 No.4,

Tae-Hoon Kim. (2001) The research regarding the determining factor of information sharing in SCM, University of Yonsei Graduate School of Information Master Degree Thesis

Tae-Hyun Kim, Seong-Am Moon. (2003) "A study of the Supply Chain Dynamics with the Symmetric Supplier's Allocation Rules" The Korean Production And Operations Management Society, Vol.14 No.1 116-136

U.M. Bhushi, C.M. Javalgi. (2000) "System Dynamics Application to Supply Chain Management: Research Review" Winter Simulation Conference Proceedings of the 32 nd conference on Winter simulation, 342 - 351 
